\title{
Friction and Wear Performance of Low-Friction Carbon Coatings under Oil Lubrication*
}

\author{
Andriy Kovalchenko, Oyelayo O. Ajayi, Ali Erdemir, and George R. Fenske \\ Energy Technology Division \\ Argonne National Laboratory \\ Argonne, IL 60439
}

\begin{abstract}
The submitted manuscript has been created by the University of Chicago as Operator of Argonne
National Laboratory under Contract No. W-31-109-ENG-38 with the U.S. Department of Energy.

The U.S. Government retains for itself, and others acting on its behalf, a paid-up, nonexclusive,

irrevocable worldwide license in said article to reproduce, prepare derivative works, distribute

copies to the public, and perform publicly and display publicly, by or on behalf of the
\end{abstract}

Government.

October 2001

Manuscript of paper to be presented at 2002 SAE Future Car Congress,

Arlington, VA, June 3-5, 2002.

\footnotetext{
*Work supported by the Department of Energy, Office of Transportation Technology, under Contract W- 31-109-Eng-38.
} 


\title{
Friction and Wear Performance of Low-Friction Carbon Coatings under Oil Lubrication*
}

\author{
Andriy Kovalchenko, Oyelayo O. Ajayi, Ali Erdemir, and George R. Fenske \\ Energy Technology Division \\ Argonne National Laboratory \\ Argonne, IL 60439 \\ Phone (630) 252-9021 \\ Fax (630) 252-4798 \\ ajayi@anl.gov
}

\begin{abstract}
:
Amorphous carbon coatings with very low friction properties were recently developed at Argonne National Laboratory. These coatings have shown good promise in mitigating excessive wear and scuffing problems associated with low-lubricity diesel fuels. To reduce the negative effect of sulfur and other lubricant additives in poisoning the after-treatment catalyst, a lubricant formulation with a low level of sulfur may be needed. Exclusion of proven sulfur-containing extreme pressure (EP) and antiwear additives from oils will require other measures to ensure durability of critical lubricated components. The low-friction carbon coating has the potential for such applications. In the present study, we evaluated the friction and wear attributes of three variations of the coating under a boundary lubrication regime. Tests were conducted with both synthetic and mineral oil lubricants using a ball-on-flat contact configuration in reciprocating sliding. Although the three variations of the coating provided modest reductions in friction coefficient, they all reduced wear substantially compared to an uncoated surface. The degradation mode of oxidative wear on the uncoated surface was replaced by a polishing wear mode on the coated surfaces.
\end{abstract}

\footnotetext{
*Work supported by the Department of Energy, Office of Transportation Technology, under Contract W- 31-109-Eng-38.
} 


\section{Introduction:}

The overall efficiency of an automotive engine strongly depends on effective lubrication of key critical components and systems. Such systems include the piston-ring and cylinder-liner interface, cam and follower, main bearing, as well as transmission. Weight and size reduction in these systems, which will result in reduced fuel consumption, will translate to higher power density and increased severity of interaction between component surfaces. This will compromise the reliability and durability of the various tribological components.

Oil formulation with an additive package to enhance the tribological performance of lubricated components has been around for some time. Anti-wear, extreme-pressure (EP), friction modifiers are usual components of additive packages. A key component in additive packages used for oil formulation is sulfur. Impending emission regulations will ultimately require a significant reduction in the sulfur content of oil lubricant. This is because sulfur is known to poison emission-reducing aftertreatment catalysts. Reduction or elimination of sulfur in oil will degrade the wear and scuffing protection attributes of the lubricant. This again will result in reliability and durability problems for various oillubricated engine components.

Means must be devised to ensure adequate reliability and durability of lubricated components. One possible means is surface modification of lubricated components, which can be done by coatings and other methods. Amorphous carbon coatings with exceptional friction and wear properties were recently developed at Argonne National Laboratory (ANL) [1-3]. The coatings have shown promise in mitigating tribological problems associated with low-lubricity diesel fuels. With these coatings, both the wear and scuffing resistance were significantly enhanced in low-sulfur, low-lubricity diesel fuels $[4,5]$.

ANL low-friction carbon coatings have the potential to improve the efficiency and at the same time enhance the reliability and durability of lubricated engine components. This paper presents the tribological performance of three different variations of the low-friction carbon coatings under boundary lubrication condition. Tests were conducted with the following oil lubricants: fully formulated synthetic oil, unformulated synthetic oil, and unformulated mineral oil. 


\section{Experimental Details:}

Coatings:

Low-friction carbon coatings were deposited on both rectangular and ball steel samples by using RF-plasma-assisted chemical vapor deposition (PACVD) method. Specimen surfaces were first sputtered cleaned in an Ar plasma, then coated with about $50-\mathrm{nm}$ Si bond layer to ensure good adhesion between the carbon coating and steel substrate. The amorphous carbon coatings were deposited from a mixture of methane and hydrogen gas plasma. By varying the ratio of hydrogen to methane, the properties and tribological behavior of the carbon coating can be controlled [3]. The three variations of the carbon coatings evaluated in the present study and some of their properties are shown in Table 1.

\section{Lubricants:}

Coated and uncoated specimen pairs were tested in three different lubricants, namely unformulated synthetic poly-alfa-olefin (PAO), fully formulated PAO, and an unformulated mineral oil. This combination of test lubricants should provide information on the effect of oil additives and the molecular structure of the base oil on the tribological performance of amorphous carbon coatings.

\section{Friction and Wear Tests:}

Friction and wear tests were conducted with a ball-on-flat contact configuration in reciprocating sliding. The 9.5 -mm-diameter ball specimens were made of hardened 52100 steel, and the rectangular flat $(50 \times 40 \times 10 \mathrm{~mm})$ samples were made of hardened H-13 tool steel. Some of the ball and flat samples were coated with the three variations of the low-friction carbon coatings. Tests were conducted in various combinations: coated balls sliding against uncoated flat, uncoated ball sliding against coated flat, uncoated ball sliding against uncoated flat, and coated ball sliding on coated flat (same type of coating).

All the tests were conducted with a normal load of $20 \mathrm{~N}$, reciprocating frequency of $1 \mathrm{~Hz}$, and a stroke length of $20 \mathrm{~mm}$ (translating to a sliding speed of $0.05 \mathrm{~m} / \mathrm{sec}$ ). All the tests were run for duration of 1 hour. In all cases, the sliding contact interface was 
fully flooded by test oil. The friction coefficient was continuously monitored for the entire testing duration. At the conclusion of each test, the wear scar diameter on the ball specimen was measured with an optical microscope. Wear volumes and wear rates were calculated from the wear scar dimension.

Worn surfaces of both ball and flat specimens were characterized by optical microscopy profilometry and scanning electron microscopy. These analyses provide insight into the operating wear mechanisms under the various test conditions.

\section{$\underline{\text { Results and Discussion: }}$}

Figure 1 shows the variation of friction coefficient with time for uncoated contact pairs when tested with the three lubricants. The average friction coefficient for the three lubricants is about 0.12 , which is typical of the boundary lubrication regime. The friction coefficient for the unformulated base-stock oils showed more variation with time when compared to the friction for formulated oil. This finding reflects the effect of the antiwear additives in the formulated oil. Reduction in wear and preservation of the surface topographical features results in minimal variation in contributions of the fluid film and surface interaction to friction. Consequently, the friction coefficient is more stable over the duration of the test. In tests with unformulated oils, as more wear occurs over time, the surface topographical features will change, and their contributions to friction will also change, and hence more variation in friction coefficient.

Figure 2 shows the friction coefficient variation over time for the different materials tested with the synthetic PAO base-stock oil. When one of the surfaces is coated, the friction coefficient shows less variation and is slightly lower than the uncoated pair. When both surfaces are coated, the friction coefficient is significantly lower compared to other cases. This finding reflects the low friction attribute of the carbon coatings. The frictional behavior shown in Fig. 2 was also observed for the other two lubricants. Among the coatings, coating 2 (NFC-6) showed the lowest friction coefficient ( 0.085 average) and coating 3 (NFC-7) showed the highest ( 0.11 average), as indicated on Fig. 3.

The most dramatic impact of the low-friction carbon coating occurred in the wear of the sliding surfaces. Figure 4 shows the wear scar diameters measured for the coated 
and uncoated balls tested with different oil. For the uncoated ball against the uncoated flat, the wear behavior for this steel-on-steel contact is determined by the wear reducing attribute of the lubricating oil. The smallest amount of wear occurred in the test with fully formulated oil, which contained anti-wear additives. Between the two base-stock oils, the mineral oil produced less wear than synthetic PAO oil, perhaps due to the presence of wear-reducing impurities, such as sulfur, in the mineral oil. Figure 5 shows optical profilometry of the typical wear scar on tests conducted with the uncoated ball and flat samples.

In all the tests conducted with coated balls sliding against an uncoated flat, no wear was observed on any of the coated balls regardless of the lubricant. Figure 6a shows the optical profilometry of a coated ball after testing, with evidence of no wear, and is typical of all the coatings. Furthermore, little or no wear was observed on the uncoated flat sample counterface. Only a few fine scratches were observed on the uncoated flat worn surface, as shown in Fig. 6b. For the uncoated ball sliding against the coated flat, no wear was observed on both the coated flats and the uncoated balls (Fig. $4 b$ ), except for the balls run against coating 2 (NFC-6). The wear with this coating was due to a local defect on the surface, which resulted in abrasive wear of the ball. The mechanisms by which the low-friction carbon coatings protect the uncoated counterface against wear are still under investigation.

For tests with the coated ball and flat specimens (Figure 4c), no significant wear was observed on the ball surfaces, except for coating 2 tested with synthetic PAO lubricant. A mild polishing wear was observed on the surface of coating 2 ball, as indicated in Fig. 7. Indeed, the wear scar is barely visible.

\section{Summary:}

Results of the present study show that Argonne's low-friction carbon coating has a significant impact on friction and wear behavior of steel surfaces in both synthetic and mineral oils. The three variations of the coating evaluated produced a modest reduction in friction coefficient, because the friction in lubricated contact is often dominated by the shearing of the lubricant fluid film. The coatings all have a significant impact on wear. Little or no wear occurred in all the coatings when slid against both coated and uncoated surfaces. More significant, all the coatings protected the uncoated counterface against 
wear. This finding suggests that coating only one of the contacting surfaces with ANL's low-friction carbon coating is as effective as coating both surfaces in minimizing wear of lubricated components. The coatings are equally effective in both synthetic and mineral oil, as well as fully formulated and base-stock oils.

Acknowledgment:

This work was supported by the U.S. Department of Energy, Office of Transportation Technology.

\section{References:}

1. A. Erdemir, O. L. Eryilmaz, and G. R. Fenske, "Synthesis of Diamondlike Carbon Films with Superlow Friction and Wear Properties,” J. Vac. Sci. Technol., A 18, (2000), 1987-1992.

2. A. Erdemir, G. R. Fenske, J. Terry, and P. Wilbur, "Effect of Source Gas and Deposition Method on Friction and Wear Performance of Diamondlike Carbon Films," Surf. Coat. Tech., 94-95, (1997), 525-530.

3. A. Erdemir, I. B. Nilufer, O. L. Eryilmaz, M. Beschliesser, and G. R. Fenske, "Friction and Wear Performance of Diamondlike Carbon Film Grown in Various Gas Plasma," Surf. Coat. Tech., 120-121, (1999), 589-593.

4. A. Erdemir, O. Ozturk, M. Alzoubi, J. Woodford, O. O. Ajayi, and G. R. Fenske, "Near-Frictionless Carbon Coatings for use in Fuel Injectors and Pump Systems Operating with Low-Sulfur Diesel Fuels,” SAE Technical Paper \# 2000-01-0518 (2000).

5. O. O. Ajayi, M. F. Alzoubi, A. Erdemir, and G. R. Fenske, "Effect of Carbon Coating on Scuffing Performance in Diesel Fuels," STLE Trib. Trans., 44, (2001), 298-304. 
Table 1: Some Properties of carbon coatings.

\begin{tabular}{|c|c|c|c|c|}
\hline Coating Type & $\begin{array}{c}\text { Plasma Gas } \\
\text { Composition }\end{array}$ & $\begin{array}{c}\text { Thickness } \\
(\mu \mathrm{m})\end{array}$ & $\begin{array}{c}\text { Hardness } \\
(\mathrm{GPa})\end{array}$ & $\begin{array}{c}\text { Elastic Modulus } \\
(\mathrm{GPa})\end{array}$ \\
\hline $\begin{array}{c}\text { Coating } 1 \\
(\mathrm{NFC}-2)\end{array}$ & $\begin{array}{c}50 \% \mathrm{CH}_{4}+ \\
50 \% \mathrm{H}_{2}\end{array}$ & 1.50 & 18 & 94 \\
\hline Coating 2 & $25 \% \mathrm{CH}_{4}+$ & 1.50 & 7 & 50 \\
$(\mathrm{NFC}-6)$ & $75 \% \mathrm{H}_{2}$ & & 20 & 135 \\
\hline Coating 3 & $100 \% \mathrm{CH}_{4}$ & 2.0 & & \\
$(\mathrm{NFC}-7)$ & & & & \\
\hline
\end{tabular}

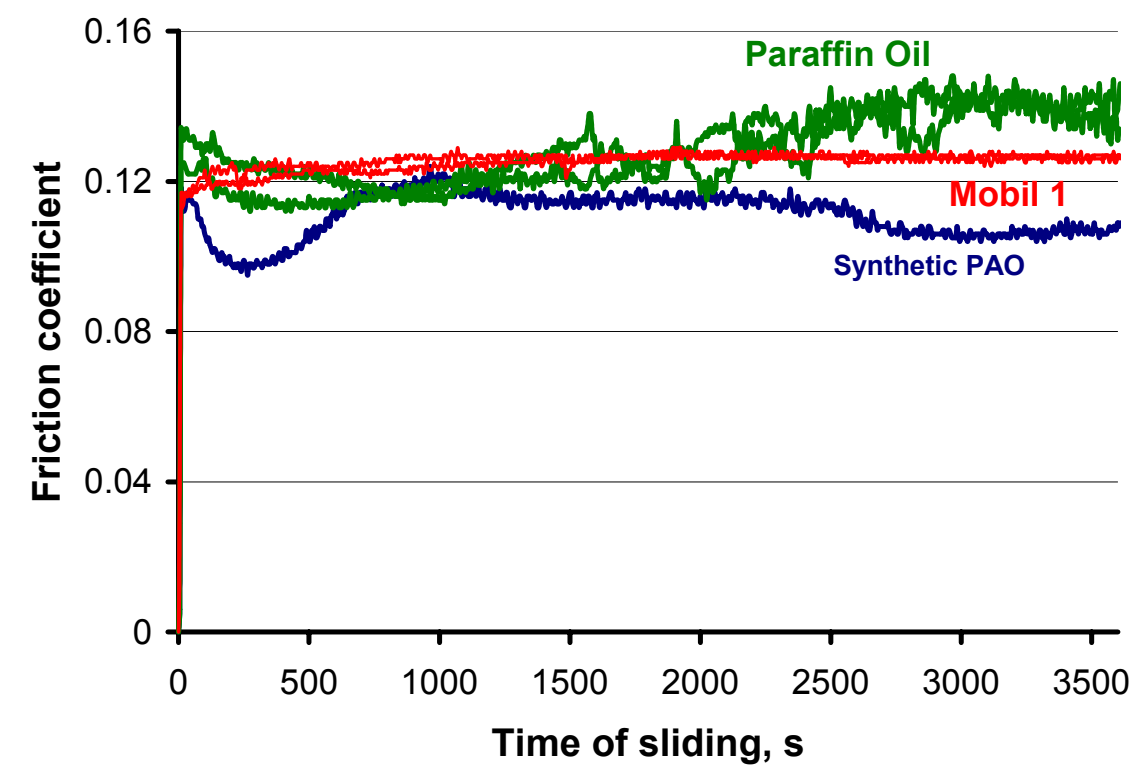

Figure 1: Variation of friction coefficients during steel-on-steel test with different oils 


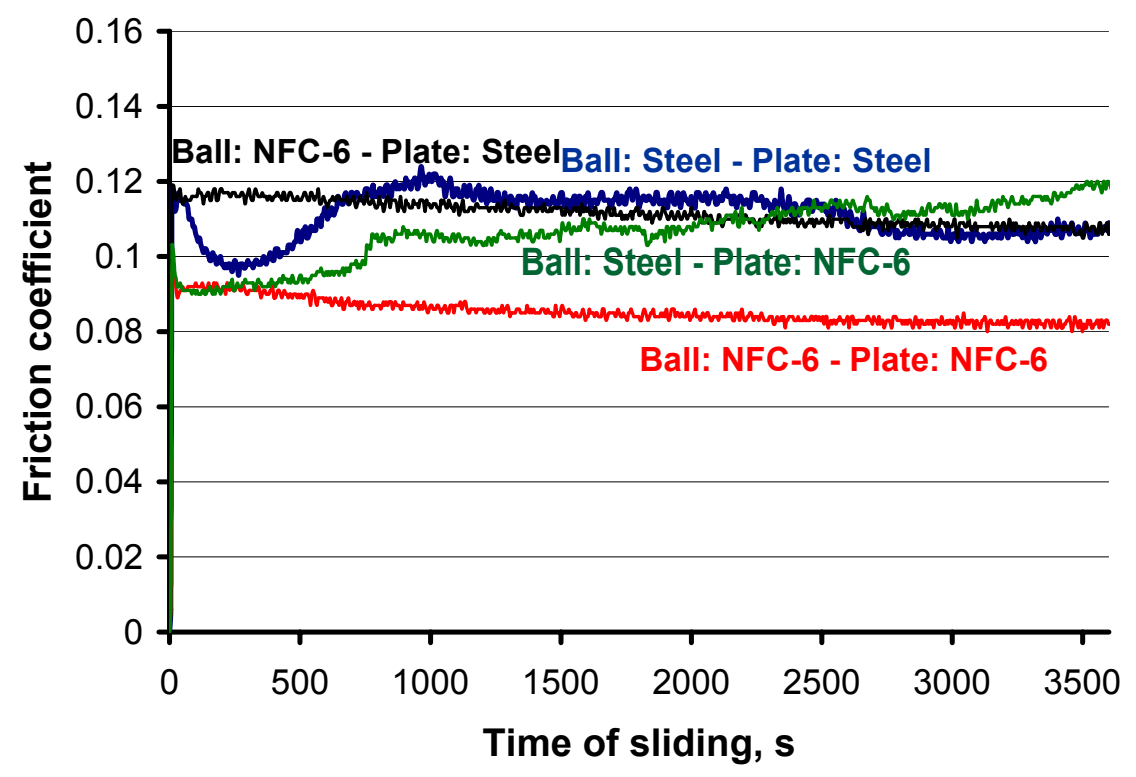

Figure 2: Variation of friction coefficients for different combinations with coating 2 (NFC-6) in base-stock POA

Friction coefficients of same material pair:

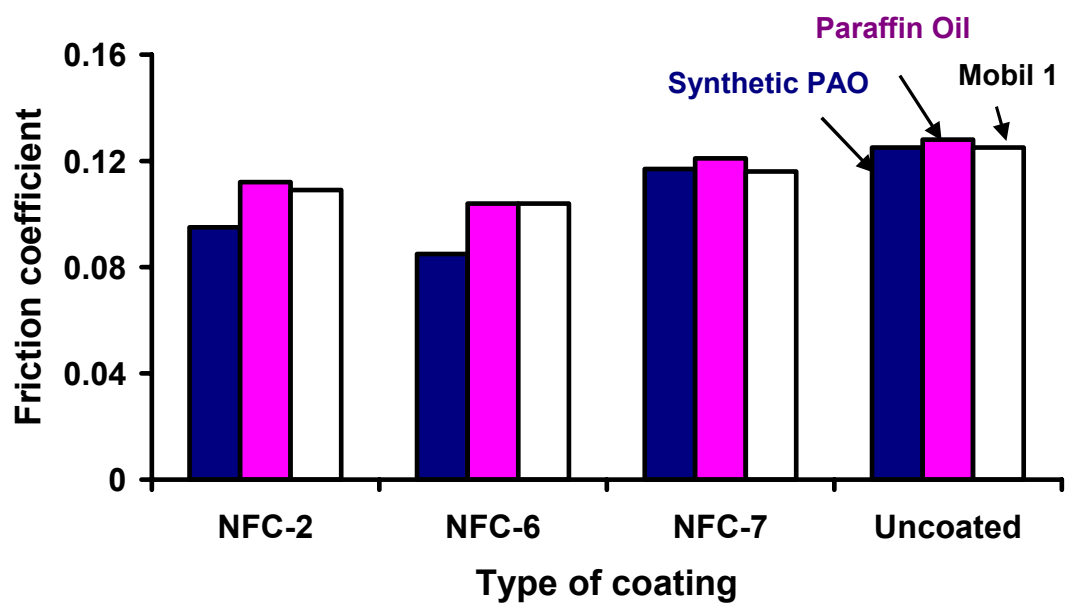

Figure 3: Average friction coefficients for same material contact pairs in different oils. 

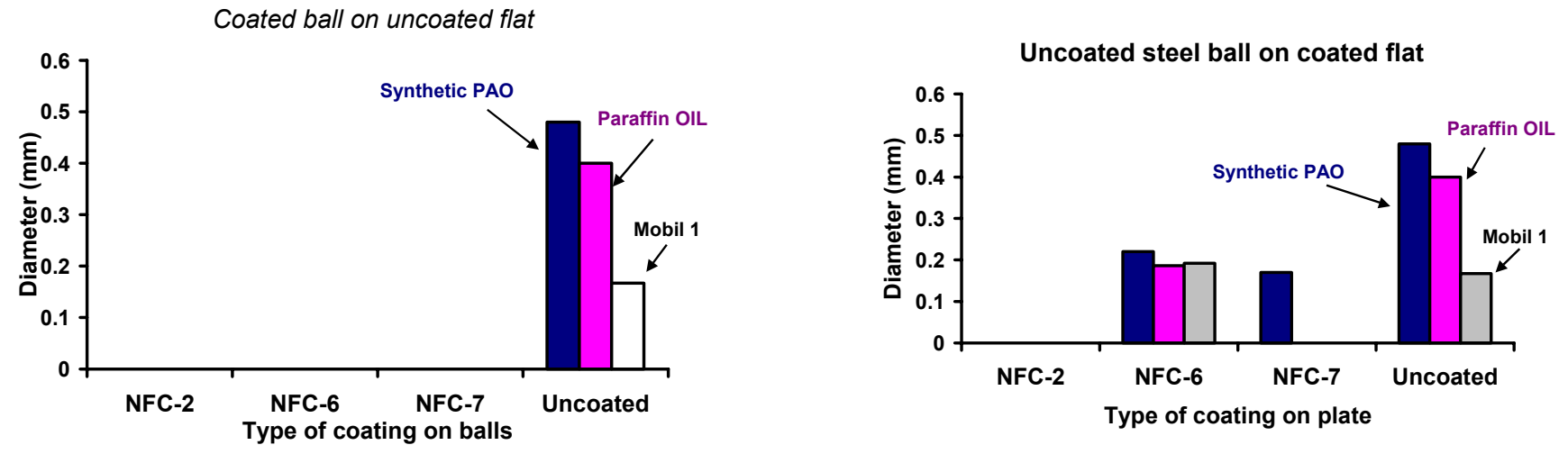

(a)

(b)

Same material pairs

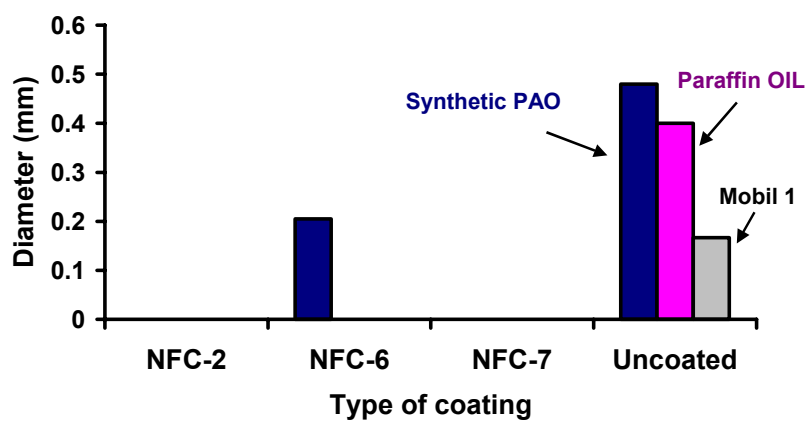

(c)

Figure 4: Ball scar diameter after testing: (a) coated balls on uncoated steel flat, (b)

Uncoated steel ball on coated flat, and (c) Same material contact pairs 


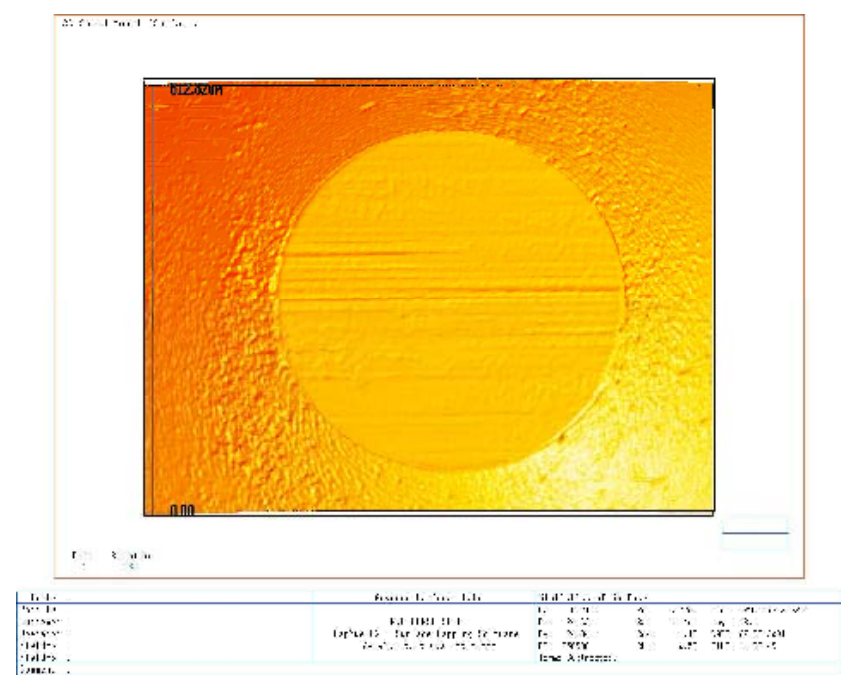

(a)

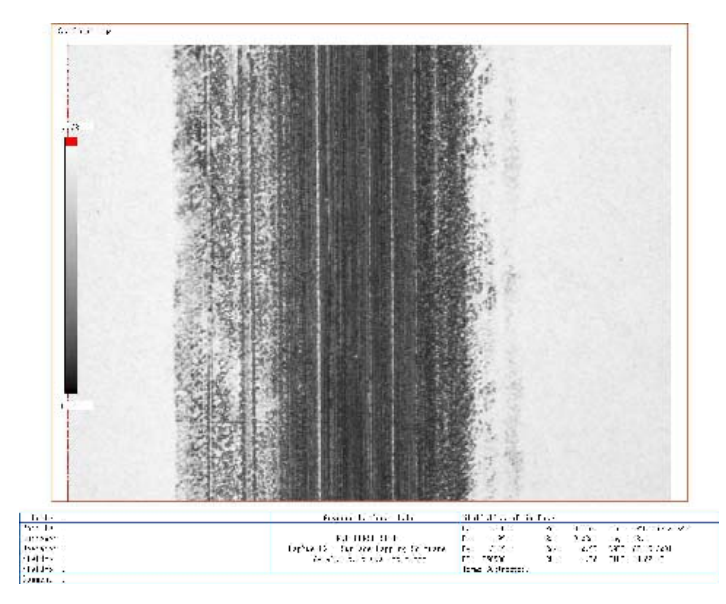

(b)

Figure 5: Optical profilometry from test of uncoated ball on uncoated flat: (a) ball, and (b) flat

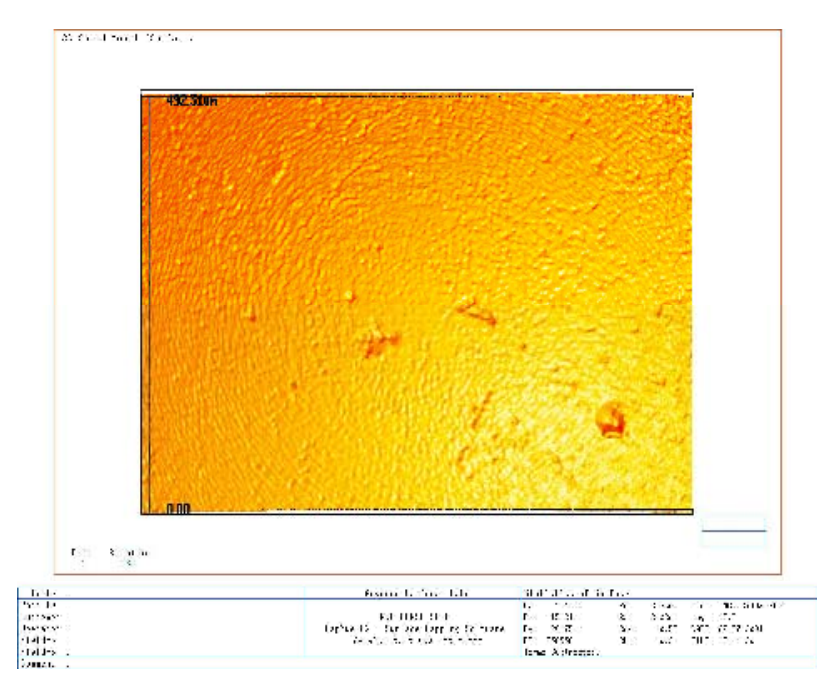

(a)

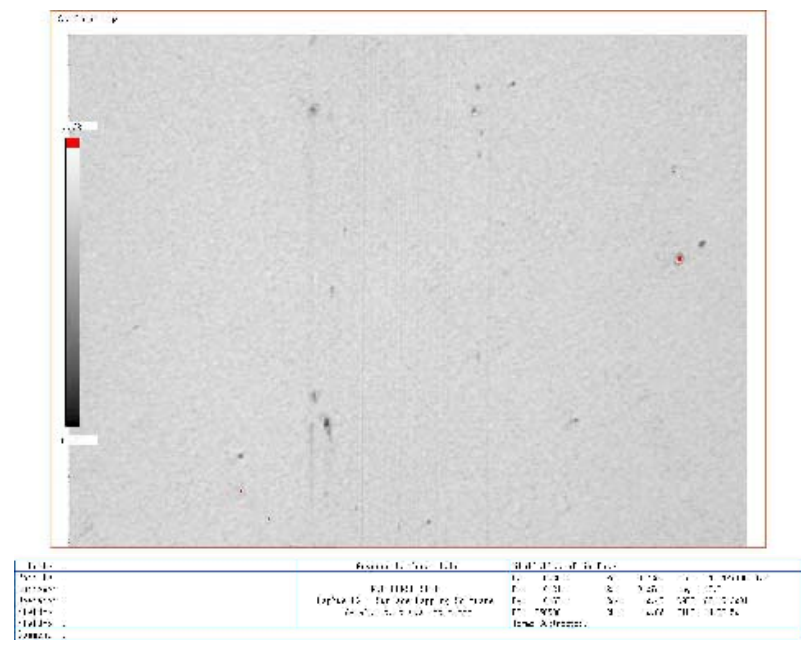

(b)

Figure 6: Optical profilometry from test of coated ball on uncoated flat: (a) ball, and (b) flat 


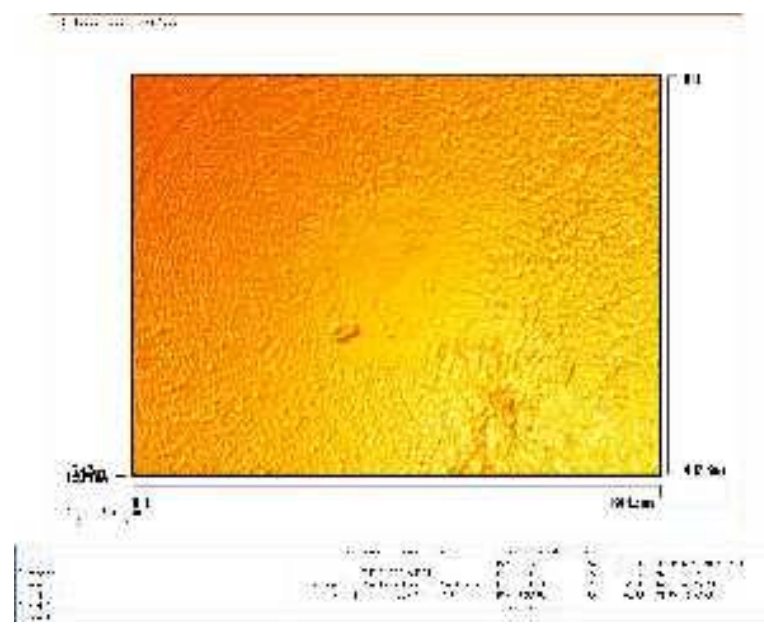

(a)

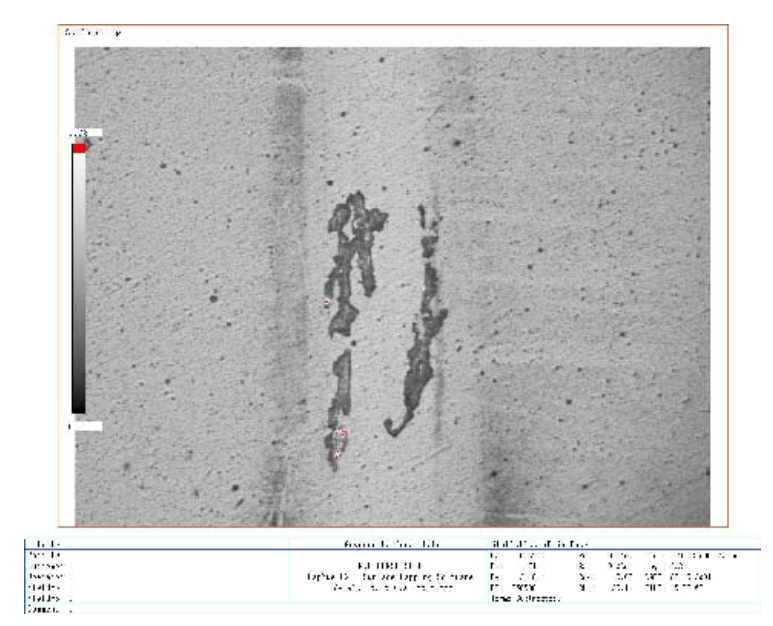

(b)

Figure 7: Optical profilometry from testof coated ball on coated flat: (a) ball, and (b) flat. 